\title{
To what extent does the size of a ventricular septal defect correlate with haemodynamic data derived from cardiac catheterisation?
}

\author{
MITSURU FUKAZAWA, * SUNAO HONDA, $†$ JUNICHIRO FUKUSHIGE, \\ HIROSHI SUNAGAWA, $\dagger$ HISATAKA YASUI, $\dagger$ KOHJI UEDA* \\ From the ${ }^{\star}$ Department of Paediatrics, Faculty of Medicine, Kyushu University; and the $\dagger$ Division of \\ Paediatric Cardiology and Cardiovascular Surgery, Fukuoka Children's Hospital Medical Centre, \\ Fukuoka, Japan
}

SUMmaRy A simplified model based on Gorlin's formula was used to derive an index of the cross sectional area of ventricular septal defects from commonly used cardiac catheterisation data. This index was compared with the area of the defect measured during operation and expressed as a ratio to the cross sectional area of the aorta. The highly significant linear relation $(r=0.94)$ between this index of the defect area and the size of the defect measured at operation means that the severity of a ventricular septal defect can be assessed from haemodynamic data obtained at cardiac catheterisation.

It is generally accepted that in patients with a ventricular septal defect the size of the defect is the most important factor determining the clinical picture and haemodynamic function ${ }^{12}$; however, little is known about how the size of the defect affects haemodynamic function. The Gorlin formula describes the relation between the shunt flow and the pressure gradient across the defect by a theorem of orifice flow. ${ }^{3}$ Because the formula does not take account of the properties of the vascular systems it cannot give a complete picture of the haemodynamic function. We have expanded Gorlin's approach and have developed a theoretical model to determine the basic relation between haemodynamic function and the anatomical size of ventricular septal defect.

\section{Patients and methods}

\section{STUDY GROUPS}

We studied 46 of the 66 children with isolated ventricular septal defect who had defects closed at Fukuoka Children's Hospital Medical Centre from

Requests for reprints to Dr Mitsuru Fukazawa, Department of Paediatrics, Faculty of Medicine, Kyushu University, 3-1-1 Maidashi, Higashi-ku, Fukuoka 812, Japan.

Accepted for publication 1 December 1986
October 1980 to November 1984. We had cardiac catheterisation data, cineangiogram records, and records obtained at operation for these cases. Age at operation ranged from three months to 13 years (median 11 months). The interval from cardiac catheterisation to operation ranged from one day to seven months (median 10 days). According to Kirklin et al's anatomical classification of ventricular septal defects ${ }^{4}$ there were 13 type I cases, 31 type II cases, and two type I + II.

\section{MODEL FOR ANALYSIS OF VENTRICULAR} SEPTAL DEFECT

An exact description of the haemodynamics of a ventricular septal defect based on fluid dynamics is difficult to devise and may not be practical to apply. We therefore used a simplified model to analyse the haemodynamics of the defect from the commonly used cardiac catheterisation data. This model assumes the following: $(a)$ that pressures in the right and left ventricles and flow rates through the aorta, the pulmonary artery, and the defect are constant during systole; $(b)$ that shunt flow through the defect only occurs from left to right; $(c)$ that left ventricular systolic pressure $\left(\mathbf{P}_{\mathbf{L V}}\right)$ and right ventricular systolic pressure $\left(\mathbf{P}_{\mathbf{R V}}\right)$ are equal to their peak systolic pressures; $(d)$ that throughout the cardiac cycle pressures in both the systemic and pulmonary 
Table Anatomical measurement and cardiac catheterisation data in 46 patients with ventricular septal defect

\begin{tabular}{|c|c|c|c|c|c|c|c|c|c|}
\hline \multirow[b]{2}{*}{$\begin{array}{l}\text { Case } \\
\text { No }\end{array}$} & \multirow[b]{2}{*}{ Age } & \multirow[b]{2}{*}{$\begin{array}{l}\text { VSD } \\
\text { type }\end{array}$} & \multicolumn{3}{|c|}{ Anatomical measurement } & \multicolumn{4}{|c|}{ Cardiac catheterisation } \\
\hline & & & $\begin{array}{l}\text { VSD dimension } \\
(m m \times m m) \dagger\end{array}$ & $\begin{array}{l}\text { Ao diameter } \\
\text { ( } \mathrm{mm})\end{array}$ & $\begin{array}{l}P A \text { diameter } \\
(\mathrm{mm})\end{array}$ & $Q_{p}: Q_{s}$ & $P_{R V}: P_{L V}$ & $R_{p}: R_{s}$ & $P_{s}: P_{L V}$ \\
\hline $\begin{array}{r}1 \\
2 \\
3 \\
4 \\
5 \\
6 \\
7 \\
8 \\
9 \\
10 \\
11 \\
12 \\
13 \\
14 \\
15 \\
16 \\
17 \\
18 \\
19 \\
20 \\
21 \\
22 \\
23 \\
24 \\
25 \\
26 \\
27 \\
28 \\
29 \\
30 \\
31 \\
32 \\
33 \\
34 \\
35 \\
36 \\
37 \\
38 \\
39 \\
40 \\
41 \\
42 \\
43 \\
44 \\
45 \\
46\end{array}$ & $\begin{array}{r}1 \mathrm{yr} 2 \mathrm{mnth} \\
9 \mathrm{mnth} \\
6 \mathrm{mnth} \\
1 \mathrm{yr} 11 \mathrm{mnth} \\
2 \mathrm{yr} 4 \mathrm{mnth} \\
8 \mathrm{mnth} \\
5 \mathrm{yr} 7 \mathrm{mnth} \\
12 \mathrm{yr} 10 \mathrm{mnth} \\
9 \mathrm{mnth} \\
10 \mathrm{mnth} \\
10 \mathrm{mnth} \\
2 \mathrm{yr} 0 \mathrm{mnth} \\
7 \mathrm{mnth} \\
11 \mathrm{mnth} \\
11 \mathrm{mnth} \\
7 \mathrm{mnth} \\
10 \mathrm{mnth} \\
3 \mathrm{mnth} \\
5 \mathrm{mnth} \\
7 \mathrm{yr} 10 \mathrm{mnth} \\
6 \mathrm{yr} 6 \mathrm{mnth} \\
7 \mathrm{yr} 3 \mathrm{mnth} \\
4 \mathrm{yr} 5 \mathrm{mnth} \\
1 \mathrm{yr} 3 \mathrm{mnth} \\
5 \mathrm{mnth} \\
3 \mathrm{yr} 4 \mathrm{mnth}\end{array}$ & $\begin{array}{l}\text { I } \\
\text { II } \\
\text { I } \\
\text { I } \\
\text { I } \\
\text { I } \\
\text { I } \\
\text { II } \\
\text { II } \\
\text { I + II } \\
\text { II } \\
\text { II } \\
\text { I } \\
\text { II } \\
\text { II } \\
\text { II } \\
\text { II } \\
\text { II } \\
\text { I } \\
\text { II } \\
\text { II } \\
\text { II } \\
\text { I + II } \\
\text { II } \\
\text { I } \\
\text { II } \\
\text { I } \\
\text { II } \\
\text { II } \\
\text { II } \\
\text { II } \\
\text { II } \\
\text { I } \\
\text { II } \\
\text { II } \\
\text { II } \\
\text { II } \\
\text { II } \\
\text { II } \\
\text { II } \\
\text { II } \\
\text { II } \\
\text { I } \\
\text { II } \\
\text { I }\end{array}$ & $\begin{array}{r}8 \times 6 \\
10 \times 10 \\
10 \times 10 \\
5 \times 3 \\
5 \times 4 \\
10 \times 9 \\
5 \times 5 \\
3 \times 3 \\
8 \times 8 \\
7 \times 7 \\
10 \times 10 \\
7 \times 7 \\
5 \times 5 \\
10 \times 10 \\
7 \times 7 \\
8 \times 8 \\
5 \times 5 \\
10 \times 10 \\
6 \times 6 \\
3 \times 3 \\
16 \times 15 \\
8 \times 8 \\
10 \times 10 \\
12 \times 12 \\
8 \times 8 \\
9 \times 9 \\
14 \times 13 \\
4 \times 4 \\
12 \times 8 \\
7 \times 7 \\
10 \times 8 \\
9 \times 8 \\
12 \times 12 \\
3 \times 3 \\
8 \times 8 \\
10 \times 10 \\
7 \times 7 \\
7 \times 7 \\
9 \times 9 \\
8 \times 8 \\
8 \times 8 \\
6 \times 6 \\
16 \times 14 \\
8 \times 5 \\
8 \times 8 \\
7 \times 7\end{array}$ & 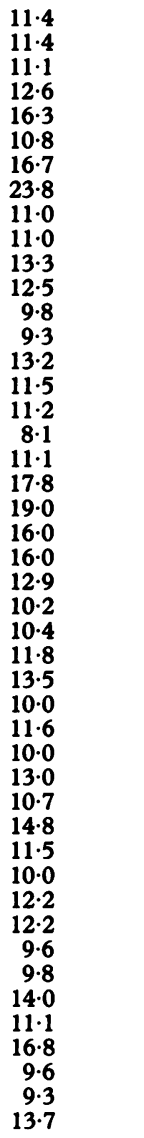 & $\begin{array}{l}15 \cdot 2 \\
18 \cdot 9 \\
15 \cdot 1 \\
16 \cdot 6 \\
21 \cdot 7 \\
18 \cdot 3 \\
24 \cdot 4 \\
28 \cdot 1 \\
19 \cdot 6 \\
17 \cdot 5 \\
20 \cdot 6 \\
19 \cdot 2 \\
12 \cdot 0 \\
24 \cdot 1 \\
18 \cdot 9 \\
19 \cdot 5 \\
14 \cdot 8 \\
11 \cdot 1 \\
16 \cdot 3 \\
21 \cdot 6 \\
26 \cdot 6 \\
21 \cdot 5 \\
23 \cdot 7 \\
17 \cdot 6 \\
16 \cdot 7 \\
16 \cdot 7 \\
23 \cdot 3 \\
17 \cdot 7 \\
15 \cdot 4 \\
19 \cdot 3 \\
18 \cdot 2 \\
20 \cdot 8 \\
20 \cdot 2 \\
16 \cdot 4 \\
16 \cdot 5 \\
14 \cdot 4 \\
18 \cdot 3 \\
17 \cdot 0 \\
15 \cdot 5 \\
13 \cdot 1 \\
17 \cdot 8 \\
15 \cdot 5 \\
20 \cdot 8 \\
18 \cdot 3 \\
14 \cdot 1 \\
21 \cdot 1\end{array}$ & 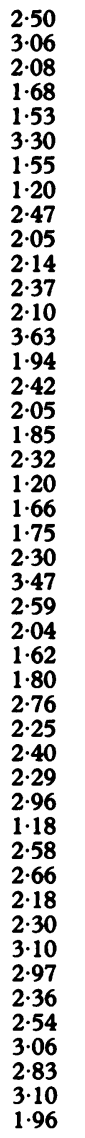 & $\begin{array}{l}0.35 \\
0.90 \\
0.98 \\
0.45 \\
0.42 \\
0.56 \\
0.34 \\
0.21 \\
0.84 \\
0.78 \\
0.88 \\
0.45 \\
0.49 \\
0.81 \\
0.59 \\
0.88 \\
0.51 \\
0.99 \\
0.72 \\
0.24 \\
0.99 \\
0.64 \\
0.38 \\
0.82 \\
0.92 \\
0.99 \\
0.99 \\
0.41 \\
0.90 \\
0.54 \\
0.97 \\
0.81 \\
0.97 \\
0.26 \\
0.69 \\
0.97 \\
0.56 \\
0.44 \\
0.82 \\
0.77 \\
0.68 \\
0.49 \\
0.91 \\
0.56 \\
0.84 \\
0.38\end{array}$ & $\begin{array}{l}0.09 \\
0.27 \\
0.53 \\
0.23 \\
0.20 \\
0.14 \\
0.17 \\
0.14 \\
0.34 \\
0.40 \\
0.46 \\
0.17 \\
0.23 \\
0.22 \\
0.24 \\
0.34 \\
0.17 \\
0.58 \\
0.26 \\
0.14 \\
0.57 \\
0.46 \\
0.09 \\
0.21 \\
0.30 \\
0.46 \\
0.76 \\
0.17 \\
0.33 \\
0.16 \\
0.36 \\
0.33 \\
0.29 \\
0.13 \\
0.25 \\
0.33 \\
0.22 \\
0.14 \\
0.23 \\
0.19 \\
0.25 \\
0.15 \\
0.24 \\
0.18 \\
0.25 \\
0.21\end{array}$ & $\begin{array}{l}0.74 \\
0.75 \\
0.67 \\
0.70 \\
0.78 \\
0.77 \\
0.79 \\
0.79 \\
0.73 \\
0.71 \\
0.70 \\
0.81 \\
0.67 \\
0.72 \\
0.72 \\
0.74 \\
0.73 \\
0.62 \\
0.77 \\
0.86 \\
0.84 \\
0.55 \\
0.67 \\
0.69 \\
0.76 \\
0.69 \\
0.65 \\
0.71 \\
0.71 \\
0.67 \\
0.71 \\
0.76 \\
0.90 \\
0.87 \\
0.70 \\
0.73 \\
0.59 \\
0.72 \\
0.72 \\
0.70 \\
0.68 \\
0.65 \\
0.89 \\
0.74 \\
0.66 \\
0.70\end{array}$ \\
\hline
\end{tabular}

*Kirklin's anatomical classification.

†Long diameter $\times$ short diameter.

VSD, ventricular septal defect; Ao, aortic; $P A$, pulmonary arterial; $Q_{p}: Q_{s}$, ratio of pulmonary blood flow to systemic blood flow; $P_{R v}: P_{L v}$, ratio of riglif: ventricular to left ventricular peak systolic pressure; $R_{p}: R_{s}$, ratio of pulmonary vascular resistance to systemic vascular resistance; $\vec{P}_{s}: P_{L v}$, ratio of meanv systemic to left ventricular peak systolic pressure.

arterial systems are constant and equal to mean vascular pressures $\left(\overline{\mathbf{P}}_{\mathrm{s}}\right.$ and $\left.\overline{\mathrm{P}}_{\mathrm{p}}\right) ;(e)$ that flow rates of blood through the defect, the aorta, and the pulmonary artery are proportional to the cross sectional area $\times \sqrt{\text { pressure gradient }}$ (Gorlin's formula. ${ }^{35}$ )

An index of the cross sectional area of the defect (AvsD index) is defined by the following equation:

$$
\begin{aligned}
A_{v S D \text { index }}=\left(Q_{p}:\right. & \left.Q_{s}-1\right) \\
& \times \sqrt{\left(1-\bar{P}_{s}: P_{L V}\right) /\left(1-P_{R V}: P_{L V}\right)},
\end{aligned}
$$

where $Q_{p}$ and $Q_{s}$ are mean pulmonary and systemic flow respectively, and the index is proportional to the ratio of cross sectional area of the defect to that of the aorta $\left(\mathrm{A}_{\mathrm{vsD}}: \mathrm{A}_{\mathrm{Ao}}\right)$, as shown in Appendix equations $9-11$. To examine this predicted relation, we compared the index of the area of the defect (AvsD index) derived from cardiac catheterisation data with the ratio of cross sectional area of the defect to that of the aorta $\left(\mathbf{A}_{\mathbf{v S D}}: \mathbf{A}_{\mathbf{A 0}}\right)$ derived from anatomical measurements.

\section{CARDIAC CATHETERISATION}

Cardiac catheterisation studies were performed during spontaneous respiration in room air after premedication, usually with $0.1 \mathrm{mg} / \mathrm{kg}$ of estazolam or 
$80 \mathrm{mg} / \mathrm{kg}$ of triclofos given orally. Pressures were measured by fluid filled catheters connected to CTC CP-01 transducers. The ratios of right ventricular to left ventricular peak systolic pressure $\left(P_{R V}: P_{L V}\right)$ and of mean systemic to peak left ventricular pressure $\left(\overline{\mathbf{P}}_{\mathrm{s}}: \mathrm{P}_{\mathrm{LV}}\right)$ were calculated. When the left ventricular pressure $\left(\mathbf{P}_{\mathrm{LV}}\right)$ was not measured, peak systemic pressure $\left(\mathbf{P}_{\mathrm{s}}\right)$ was used. The pulmonary to systemic blood flow ratio $\left(Q_{p}: Q_{s}\right)$ and the pulmonary to systemic vascular resistance ratio $\left(\mathbf{R}_{\mathrm{p}}: \mathbf{R}_{\mathbf{s}}\right)$ were calculated by the Fick method. The oxygen saturation of haemoglobin was measured by spectrophotometer. Oxygen saturation was used instead of oxygen content to calculate $Q_{p}: Q_{s}$, and the content of dissolved oxygen was ignored. The oxygen saturation of mixed venous blood was measured in blood samples from the superior vena cava and the inferior vena cava with the ratio of 3 to $1 .^{6}$ The oxygen saturation of pulmonary arterial blood was measured as the average of samples from both pulmonary arterial branches or in one of them; oxygen saturation of systemic arterial blood was measured in samples from the femoral artery or the aorta. Because the blood of the pulmonary vein could not be sampled in most cases, the oxygen saturation was assumed to be the same as that of systemic arterial blood, ignoring the right to left shunt. Because left atrial pressure or pulmonary capillary wedge pressure was not always available we used total pulmonary vascular resistance. The index of defect area (AvsD index) was calculated from these data.

\section{MEASUREMENTS OF CROSS SECTIONAL AREA}

The diameters of the aorta and the pulmonary artery were measured at the level of the valve ring on lateral view cineangiograms. At angiography the aortic valve ring was located near the centre of the lateral image screen and had a diameter of $250 \mathrm{~mm}$. The distance between the $x$ ray tube and the image screen was fixed at $900 \mathrm{~mm}$, and the object was placed approximately $200 \mathrm{~mm}$ from the image screen. We placed a screen with a lead grid in parallel with the lateral image screen at the midpoint of the aortic valve ring to measure the dimensions of the aorta and the pulmonary artery. As a guide we used the anteroposterior angiogram recorded by video tape. The cross sectional areas of the aorta $\left(A_{A_{0}}\right)$ and of the pulmonary artery $\left(\mathrm{A}_{\mathrm{PA}}\right)$ were calculated from the following formula, assuming a circular cross sectional contour: area $=1 / 4 \times \pi \times D^{2}$, where $\mathrm{D}$ was defined as the mean value of maximum and minimum diameter during one cardiac cycle. Since the size of the defect in the beating heart cannot be determined exactly, we measured the size in the arrested heart with sterile callipers during operation. We assumed that the size of the defect in the beating heart had the same relation with that in the arrested heart. The long and short diameters $\left(D_{L}\right.$ and $\left.D_{S}\right)$ were measured and the cross sectional area (AvsD) was calculated, assuming that the defect was ellipsoidal, by means of the following formula: $A_{V S D}=1 / 4 \times \pi \times$ $D_{L} \times D_{s}$.

\section{Results}

The table shows the anatomical measurements and cardiac catheterisation data in 46 patients. The figure shows the relation between the index of the area of the defect (AVSD index $)$ and the measured defect area expressed as a ratio to the aortic area $\left(A_{\mathrm{vsD}}: \mathrm{A}_{\mathrm{AO}}\right)$. The linear regression equation was:

$$
\begin{aligned}
& A_{V S D}: A_{A 0}=0.28 \times A_{\text {VSD index }}+0.02 \\
& (r=0.94, n=46, p<0.001) \text {. }
\end{aligned}
$$

The highly significantly linear relation between $A_{V S D}$ index and $A_{V S D}: A_{A o}$ and the negligible $y$ axis intercept indicates that the index of the area of the defect derived from cardiac catheterisation data is proportional to the ratio of the area of the defect to the aortic area.

\section{Discussion}

The model we proposed for the assessment of the haemodynamic function of a ventricular septal defect is simple but its application depends on various assumptions. Our results show a basic relation

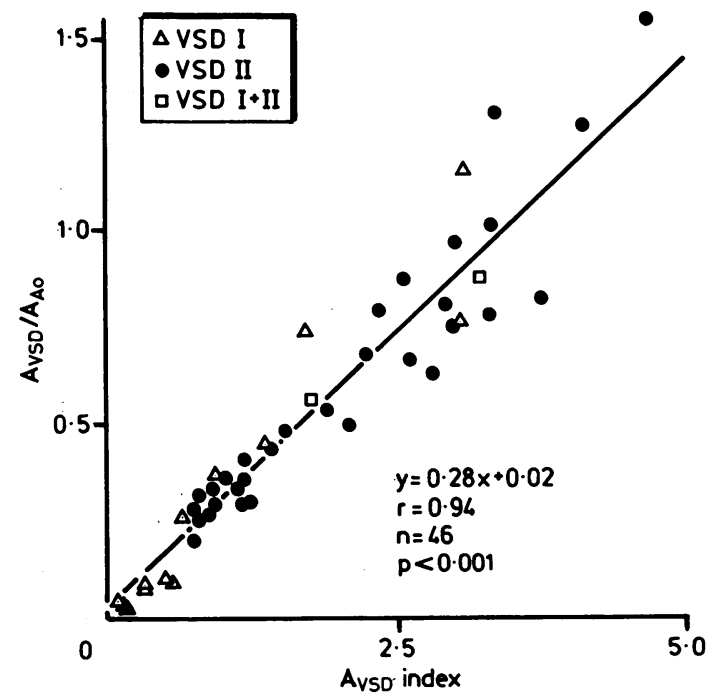

Figure Correlation between the index of cross sectional area of the defect $\left(A_{V S D}\right.$ index $)$ derived from the cardiac catheterisation data and the ratio of cross sectional area of the defect to that of the aorta $\left(A_{V S D}: A_{A o}\right)$ derived from the anatomical measurements. 
between haemodynamic function and the anatomy of the defect; they also suggest that it is important to standardise the size of the defect according to cross sectional area of the aorta rather than to use the defect size itself.

Cardiac catheterisation is used to evaluate the severity of ventricular septal defect and to determine indications for operation. Usually three haemodynamic indices (that is pulmonary to systemic blood flow ratio $\left(Q_{p}: Q_{s}\right)$, pulmonary to systemic systolic pressure ratio $\left(\mathbf{P}_{\mathbf{p}}: \mathbf{P}_{\mathbf{s}}\right)$, and pulmonary to systemic vascular resistance ratio $\left.\left(\mathbf{R}_{\mathbf{p}}: \mathbf{R}_{\mathbf{s}}\right)\right)$ are used for such assessment. ${ }^{78}$ The fact that these variables are not mutually independent sometimes makes it difficult to evaluate the severity of the defect from cardiac catheterisation data. We think that a reasonable assessment can be made by using two independent indices. That is the index of defect area (AvsD index), which represents the size of the defect, and the ratio of pulmonary vascular resistance to systemic vascular resistance $\left(\mathbf{R}_{\mathrm{p}}: \mathbf{R}_{\mathbf{f}}\right)$, which represents the vascular property. Apart from six children with a type I ventricular septal defect who were treated to prevent aortic regurgitation caused by prolapse of the aortic cusp, all the others, whose surgical indications were determined mainly from the usual criteria (that is $Q_{p}: Q_{s}>2$ or $P_{p}: P_{s}>0.5$ ), had indices for the area of the defect of $>0.75$ and ratios of defect area to aortic area of $>0.2$. We therefore consider that surgical intervention is not imperative in patients in whom the index of area of the defect is $<0.75$, except when they have a type I ventricular septal defect. This criterion for operation corresponds to a defect to aortic diameter ratio of about 0.5 in the case of a round defect.

Equations 12 and 13 in the appendix show that our model also allows estimation of the commonly used haemodynamic indices (that is the ratio of pulmonary to systemic blood flow $\left(Q_{p}: Q_{s}\right)$ and the ratio of right ventricular to left ventricular peak systolic pressure $\left(\mathbf{P}_{\mathrm{RV}}: \mathbf{P}_{\mathrm{LV}}\right)$ ) from the two anatomical values (that is the ratio of the defect area to the aortic area $\left(A_{V s D}: A_{A_{0}}\right)$ and the ratio of the pulmonary arterial area to the aortic area $\left(A_{\left.P_{A}: A_{A 0}\right)}\right)$ and the two vascular indices (that is the ratio of pulmonary vascular resistance to systemic vascular resistance $\left(R_{p}: R_{s}\right)$ and the ratio of mean systemic pressure to systolic systemic pressure $\left.\left(\mathbf{P}_{\mathbf{s}}: \mathbf{P}_{\mathbf{s}}\right)\right)$. There was a linear relation between the haemodynamic indices estimated from the model $\left(Q_{p}: Q_{s \text { est }}\right.$ and $P_{R v}: P_{L V}$ est $)$ and those derived directly from cardiac catheterisation $\left(Q_{p}: Q_{s}\right.$ cath and $P_{R V}: P_{L V}$ cath). The linear regression equations were:

$$
\begin{aligned}
& Q_{p}: Q_{s \text { cath }}=0.93 \times Q_{p}: Q_{s ~ e s t}+0.20 \\
& (r=0.92, n=46) \text {, }
\end{aligned}
$$

and

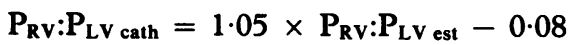

$$
\begin{aligned}
& (r=0.94, n=46) \text {, }
\end{aligned}
$$

respectively. These results indicate the usefulness of this model and suggest that the haemodynamic features of ventricular septal defect are determined mainly by anatomical values (that is $A_{v s D}: A_{A o}$ and $A_{P A}: A_{A 0}$ ) and the vascular properties (that is $R_{p}: R_{s}$ and $\bar{P}_{\mathbf{s}}: \mathbf{P}_{\mathbf{s}}$ ).

In conclusion, the index of cross sectional area of the defect, deduced from our model, links haemodynamic function with anatomy. That is, this index of area of the defect, calculated from the cardiac catheterisation data, correlates well with the area of the defect expressed as a ratio to the aortic area. This index may be used to grade the severity of the disease. We are now applying this method to the estimation of haemodynamic function from echocardiographic measurements.

\section{Appendix}

MODEL OF VENTRICULAR SEPTAL DEFECT

Adopting the assumptions described above, we constructed a model of ventricular septal defect. According to the Gorlin formula, flow rates through the aorta $\left(F_{A_{0}}\right)$, through the pulmonary artery $\left(F_{P_{A}}\right)$, and through the defect ( $\left.F_{V S D}\right)$ during systole are expressed as:

$$
\begin{aligned}
\mathbf{F}_{\mathrm{Ao}} & =\alpha_{1} \times \mathbf{A}_{\mathrm{Ao}} \times \sqrt{\left(\mathbf{P}_{\mathrm{LV}}-\overline{\mathbf{P}}_{\mathrm{s}}\right)} \\
\mathrm{F}_{\mathrm{PA}} & =\alpha_{2} \times \mathbf{A}_{\mathrm{PA}} \times \sqrt{\left(\mathbf{P}_{\mathrm{RV}}-\overline{\mathbf{P}}_{\mathrm{p}}\right)} \\
\text { and } \mathrm{F}_{\mathrm{VSD}} & =\beta \times \mathbf{A}_{\mathrm{VSD}} \times \sqrt{\left(\mathbf{P}_{\mathrm{LV}}-\mathbf{P}_{\mathrm{RV}}\right)},
\end{aligned}
$$

where the empirical coefficients for $F_{A 0}, F_{P A}$, and $F_{V S D}$ are $\alpha_{1}, \alpha_{2}$, and $\beta$ respectively; and $A_{A 0}, A_{P A}$, and AvsD are the cross sectional area of the aorta, pulmonary artery, and septal defect respectively.

$$
\begin{gathered}
F_{P A} \text { is the sum of } F_{A 0} \text { and } F_{V S D} \text { as } \\
\qquad F_{P A}=F_{A 0}+F_{V S D} .
\end{gathered}
$$

Systemic vascular resistance $\left(\mathbf{R}_{\mathbf{s}}\right)$ and pulmonary vascular resistance $\left(R_{p}\right)$ are determined as

$$
\begin{aligned}
\mathbf{R}_{\mathbf{s}} & =\overline{\mathbf{P}}_{\mathbf{s}} / \mathbf{Q}_{\mathbf{s}} \\
\text { and } \mathbf{R}_{\mathbf{p}} & =\overline{\mathbf{P}}_{\mathbf{p}} / \mathbf{Q}_{\mathbf{p}},
\end{aligned}
$$

where $Q_{s}$ and $Q_{p}$ are mean systemic flow and mean pulmonary flow.

The relation between $F_{A o}$ and $Q_{s}$, and $F_{P A}$ and $Q_{p}$ can be described as

$$
\begin{aligned}
F_{A 0} & =Q_{s} \times\left(T / T_{s}\right) \\
\text { and } F_{P A} & =Q_{p} \times\left(T / T_{s}\right),
\end{aligned}
$$




\section{Size of ventricular septal defect derived from catheterisation}

where $T$ and $T_{s}$ are the duration of one cardiac cycle and of systolic interval.

From the above simultaneous equations (1)-(8), the following equation can be deduced as

$$
\begin{aligned}
A_{\mathrm{VSD}}: \mathbf{A}_{\mathrm{Ao}}=\left(\alpha_{1} / \beta\right) \times\left(\mathbf{Q}_{\mathrm{p}}: \mathbf{Q}_{\mathrm{s}}-1\right) \times \\
\sqrt{\left(1-\overline{\mathbf{P}}_{\mathrm{s}}: \mathbf{P}_{\mathrm{LV}}\right) /\left(1-\mathbf{P}_{\mathrm{RV}}: \mathbf{P}_{\mathbf{L V}}\right)} .
\end{aligned}
$$

Here index of cross sectional area of the defect $\left(A_{\text {VSD index }}\right)$ is defined as

$A_{\text {VSD index }}=\left(Q_{p}: Q_{s}-1\right) \times$

$$
\sqrt{\left(1-\bar{P}_{s}: P_{L V}\right) /\left(1-P_{R V}: P_{L V}\right)} \text {. }
$$

Substituting $A_{V S D \text { index }}$ equation (9) can be rewritten as

$$
\mathrm{A}_{\mathrm{VSD}}: \mathbf{A}_{\mathrm{Ao}}=\left(\alpha_{1} / \beta\right) \times \mathbf{A}_{\mathrm{VSD} \text { index }},
$$

which indicates the proportional relation between AvsD index $_{\text {and }} \mathbf{A}_{\mathbf{V S D}}: \mathrm{A}_{\mathrm{AO}}$.

The second degree equation for $\mathrm{Q}_{\mathrm{p}}: \mathrm{Q}_{\mathrm{s}}$ also can be deduced from the above equations as:

$\left[\left(A_{P A}: A_{A_{0}}\right)^{2}+\left(A_{\text {VSD index }}\right)^{2}\right] \times\left(Q_{p}: Q_{s}\right)^{2}+$

$\left[\gamma \times\left(\mathbf{A}_{\mathrm{VSD} \text { index }}\right)^{\mathbf{2}} \times\left(\mathbf{R}_{\mathbf{p}}: \mathbf{R}_{\mathrm{s}}\right)-2\right] \times\left(\mathbf{A}_{\mathbf{P A}}: \mathbf{A}_{\mathbf{A 0}}\right)^{2} \times$

$\left(Q_{p}: Q_{s}\right)+\left[1-(1+\gamma) \times\left(A_{\text {VSD index }}\right)^{2}\right] \times$

$\left(A_{P A}: A_{A o}\right)^{2}=0$,

where the empirical coefficients $\alpha_{1}$ and $\alpha_{2}$ are assumed to be the same, and $\gamma$ is defined as $\gamma=1 /\left[\left(\mathbf{P}_{\mathbf{L v}}: \overline{\mathbf{P}}_{\mathbf{s}}\right)-1\right]$.

Similarly $P_{R V}: P_{L V}$ can be deduced as
$\mathbf{P}_{\mathrm{RV}}: \mathbf{P}_{\mathrm{LV}}=\left[(1 / \gamma) \times\left(\mathbf{A}_{\mathrm{Ao}}: \mathbf{A}_{\mathbf{P A}}\right)^{2} \times\left(\mathbf{Q}_{\mathrm{p}}: \mathbf{Q}_{s}\right)^{2}+\right.$ $\left.\left(\mathbf{R}_{\mathrm{p}}: \mathbf{R}_{\mathrm{s}}\right) \times\left(\mathbf{Q}_{\mathrm{p}}: \mathbf{Q}_{\mathrm{s}}\right)\right] \times\left(\overline{\mathbf{P}}_{\mathrm{s}}: \mathbf{P}_{\mathbf{L V}}\right)$.

$\overline{\mathrm{P}}_{\mathrm{s}}: \mathrm{P}_{\mathrm{s}}$ was used instead of $\overline{\mathrm{P}}_{\mathrm{s}}: \mathrm{P}_{\mathrm{LV}}$ in the calculation.

We thank Dr Kenji Sunagawa for discussion and Mariko Ohara for comments. 


\section{References}

1 Selzer A. Defect of the ventricular septum. Arch Intern Med 1949;84:798-825.

2 Damman JF, Thompson WM, Sosa O, Christlieb I. Anatomy, physiology and natural history of simple ventricular septal defects. Am $\mathcal{F}$ Cardiol 1960;5: 136-66.

3 Gorlin R, Gorlin SG. Hydraulic formula for calculation of the area of the stenotic mitral valve, other cardiac valve, and central circulatory shunts. I. Am Heart f 1951;41:1-29.

4 Kirklin JW, Harshbarger HG, Donald DE, Edwards JE. Surgical correction of ventricular septal defect: anatomic and technical considerations. F Thorac Surg 1975;33:45-59.

5 Milnor WR. Hemodynamics. Baltimore: Williams and Wilkins, 1982:23-4.

6 Yang SS, Bentivoglio L, Maranhao V, Goldberg H. From cardiac catheterization data to hemodynamic parameters. Philadelphia: FA Davis, 1978:211.

$7 \mathrm{McNamara}$ DG. Medical problems in correction of ventricular septal defects. Prog Cardiovasc Dis 1965;8:44-59.

8 Cartmill TB, DuShane JW, McGoon DC, Kirklin JW. Results of repair of ventricular septal defect. $\mathcal{f}$ Thorac Cardiovasc Surg 1966;52:486-501. 